\title{
E-Commerce and Internet Marketing in Yemen: Opportunities and Challenges
}

\author{
Ahmed Al-Halili and Li Hongxin \\ School of Management Science and Engineering, Dongbei University of Finance and Economics, Dalian, \\ P.R. China
}

\begin{abstract}
Nowadays, information and communication technologies (ICT) are advancing in a fast speed. It is widely acknowledged that businesses can benefit a lot from the process of applying the advanced technology in both B2B and B2C Marketing. For example, both the behaviors of buying and selling can be completed based on Internet and information system, and this is called e-Commerce. Under this situation, the internet marketing has emerged. It is represented by e-Marketplace which is known as a virtual place. The emergence of e-platforms is helpful for businesses to find more customers and finish the business transactions effectively and efficiently. Despite the limitations and obstacles in adopting and implementing e-commerce, SMEs can still enjoy the benefits of ecommerce. Yemen is still developing the basic elements of an e-commerce infrastructure such as networking, electronic payments and IT-related services, including information technology education and training. Yemen has recently gained higher mobile subscriptions and Internet access penetration rates. The increased use and popularity of mobile phones in Yemen has opened the door to large-scale introduction of e-commerce. Due to the high penetration rate and infrastructure construction, Yemen has good potential to apply ICT and e-commerce.

However, Yemeni e-commerce must overcome the lack of experience and skills such as ICT and e-commerce, the concentration of ICTs in urban areas, and the shortage of information technology personnel and facilities. The document suggests that effective e-commerce adoption and implementation should be conducted under carefully designed national ICT and e-commerce development plans and guidelines.
\end{abstract}

Keywords: Electronic commerce, information and communication technology, electronic business, mobile commerce, developing countries, technology transfer, emerging economies, digital economy, Middle East, Yemen.

DOI: $10.7176 / \mathrm{EJBM} / 11-21-04$

Publication date:July $31^{\text {st }} 2019$

\section{Introduction}

In the modern world, businesses pay more attention to the usage of information systems in business relationships. In past few decades, business can be operated by using some new methods, and these ways are represented by ecommerce and marketing online. From the perspective of Samanta \& Kyriazupoulos (2008), Internet plays an important role in the operation process of business-to-business (B2B), and this is because that it can make the communication of buyers and sellers become very effective. After having taken different e-commerce forms into consideration, it is easy to find that e-commerce is an important platform for companies which are relatively small. These small companies are facing great challenges in finding its target customers. Some popular websites such as Alibaba.com offer chances to purchase and distribute products online in an efficient way.

The Internet is becoming inevitable. Technology shapes all aspects of life - society, economy, politics and lifestyle. Everyday there is a new use of the Internet. This article discusses the Internet usage in Yemen. It demonstrates that e-commerce still has a great potential in the future market. Based on the current situation, it is no difficulty to find that Yemen does not very well in using Internet and its awareness in this aspect need to be improved (Al-wazir \& Zheng, 2014). To be specific, Yemeni people can find more chances on the Internet in the near future. Information technology and communication are considered to be important "carriers" for sustained development of economy (Pârgaru \& Rotaru, 2012). After having taken the exact situation of the international trading into account, Terzi (2011) believe that low-income countries can benefit a lot from the emergence of e-commerce, and one of the most obvious one is that it can help these countries to improve their income. There is no denying the fact that a lot of countries in Middle East are very poor and e-commerce can provide different economic wealth for these countries. This article will focus on talking about the major challenges and opportunities of e-commerce on the Yemeni people.

Earlier studies suggested that small and medium enterprises (SMEs) could benefit from implementing the Internet whereby and marketing activities are effectively and efficiently undertaken. Internet can help business-to-business (B2B) marketers by allowing online quotes, advertising in more markets, and providing e-mail to directly 
communicate with the customers. The cost of advertising and communication on the Internet is much lower than traditional communication methods. In order to improve credibility, B2B marketers can create professional images through efficient websites, give answers to the questions about products with various languages, and organize researches in the foreign markets (McCue, et al., 2007).

Not only B2B marketers see Internet as platform to link with their business customers and to build up business's relationships, the mass consumer market can be also reached effectively via Internet, thus B2C marketers took opportunities of advances in the Information technology to offer their products. The pioneers in this category are Amazon.com and eBay, Nowadays, almost all businesses are having their own websites which can offer real time information to consumers and also makes possible to undertake business transactions like ordering or purchase, payment and follow-up. Internet marketing is increasing even in developing countries.

\subsection{Background of the development in ICT sector in Yemen}

Table 1 shows statistics to compare Yemen with other countries regarding the information and communication technologies.

Table 1: Data of Information \& Communication Technologies in different countries by comparing with Yemen

\begin{tabular}{|l|r|r|r|r|r|r|r|}
\hline \multicolumn{2}{|c|}{$\begin{array}{l}\text { e- commerce users out of } \\
\text { internet population }\end{array}$} & $\begin{array}{c}\text { e- Commerce } \\
\text { \$ Spending } \\
\text { per e- } \\
\text { Commerce } \\
\text { user a year }\end{array}$ & $\begin{array}{c}\text { e- Commerce } \\
\text { market size } \\
\text { (B\$) }\end{array}$ & $\begin{array}{c}\text { Fixed (wired)- } \\
\text { broadband } \\
\text { subscriptions } \\
\mathbf{( , 0 0 0 )}\end{array}$ & $\begin{array}{c}\text { Fixed (wired)- } \\
\text { broadband } \\
\text { subscriptions } \\
\text { per 100 } \\
\text { inhabitants }\end{array}$ & $\begin{array}{c}\text { Fixed- } \\
\text { telephone } \\
\text { subscriptions } \\
\mathbf{( , 0 0 0 )}\end{array}$ & $\begin{array}{c}\text { Fixed- } \\
\text { telephone } \\
\text { subscriptions } \\
\text { per 100 } \\
\text { inhabitants }\end{array}$ \\
\hline USA & $80 \%$ & 1,111 & 193.0 & 91,342 & 29.25 & 135,127 & 42 \\
\hline China & $71 \%$ & 799 & 159.0 & 188,909 & 10.08 & 266,985 & 19 \\
\hline Brazil & $20 \%$ & 850 & 11.0 & 20,190 & 13.63 & 45,038 & 22 \\
\hline Indonesia & $6 \%$ & 256 & 0.9 & 3,251 & 1.30 & 30,722 & 12 \\
\hline Yemen & $3 \%$ & 120 & 0.1 & 276 & 1.10 & 1,163 & 8 \\
\hline
\end{tabular}

Sources: Federal Communications Commission, USA; Ministry of Industry and Information Technology, China; Ministry of

Industry and Information Technology, Brazil; MCIT, Indonesia; ITU estimate, Yemen. Data as of 2017.

\subsubsection{Government}

The Yemen's e-government can make important and obvious progress in a short time. It is reported that the egovernment plays an important role in fighting with corruption and improving policy development (Bhat, 2014). For the Yemeni governments, they are facing different challenges in implementing e-government. As one of the lowest ranked countries, Yemen plays an indispensable role in revealing the factors which are valued by the United Nations (Al-Aghbari et al., 2015). Al-wazir \& Zheng (2014) claim that leadership and management are two key challenges, also the infrastructure costs cannot be ignored. The Yemeni online service is the index which needs to be strengthened most (A. Ali \& Zhao, 2012).

When it comes to the e-commerce laws and regulations, the one which is very close to Yemen is "Act No. 40 of the 2006 Electronic Payment System for Finance and Banking". The law recognizes the court's electronic payments, financial and banking transactions. Under this situation, the electronic signatures and transactions can achieve legitimacy from here.

The government has the ability to predict the telecommunications development trend and information technology development trend. For the government, it can be considered as the sole monopolist of Internet services by taking Tele Yemen and Yemen into consideration. Although Tele Yemen owns different stakes in the government, Yemen is fully controlled by its government. From the perspective of Internet users, they are not satisfied with the lack of service and Internet access's availability.

Besides, the government makes its decision to send e-mail at the beginning of the 21 st century. Under this situation, it is really a pity that the project cannot get a correct understanding of the e-commerce's perceptions. To be honest, there are different problems in this project. It is controlled by an office with technical project management capabilities. The system has issues with availability and this is difficult to use. As an electronic funds transfer (EFT) system, the system is used as an electronic wallet. For users, they are willing to buy emails and then put them on 
different cards. Not all e-mails can be put in related parties, and this causes customers to be dissatisfied with email. No one central database can be found in the power companies and these companies can be connected to an electronic database.

\section{E-COMMERCE IN YEMEN AND THE WORLD}

To accelerate the use of e-commerce services in Yemen, there should be some initiatives to understand the mentality of Yemenis and get over the culture and customs barriers and ease the mistrust relationship between government and citizens.

Specifically, more and more international electronic transaction has been finished through international network, and the first one was taken place in 2005. After having experienced ATM culture's penetration which is very high, the transaction growth rate was low in 2011. Prior to writing this article, it is impossible for local banks to provide an internet business account. This is because that the local banking transactions infrastructure is facing different network problems. Moreover, these problems can lead to the emergence of security issues and economic difficulties.

In 2014, the World Bank implements an advanced electronic transfer system, and incorporating credit bureaus, real-time total settlement (RTGS) and modern core banking systems into electronic interbank transactions to improve the usage of local payment systems. The grant intends to apply better information technology to the financial system. Oman has experienced an effective process in implementing its payment system (S. Ali \& AlJabri, 2011). For the Yemeni Central Bank, it can benefit a lot from this.

Online banking has a close relationship with a personal bank whose service is very limited. Banks keep on working very hard so as to achieve reliable service. It is widely acknowledged that the electronic bill payment systems can be offered by banks. As to the Internet fraud, it is actually a kind of risk that banks have to bear.

\section{E-Commerce, Internet Marketing and E-Marketplace}

The WWW (World Wide Web) has changed the way of doing business, and some new business platforms and systems have emerged, such as e-commerce. E-commerce means research through digital interaction technology. Gilmore et al. (2007) say that it is consistent with both e-commerce and e-marketing. Generally speaking, ecommerce can be bought and sold through the Internet, and it is characterized by borderlessness and uncertainty ( $\mathrm{Hu}, \mathrm{Wu}$ and Wang, 2009). As to the definition of the electronic marketing, it can be related to establish and maintain customer relationships by making full use of electronic methods or media through electronic platforms (such as the B2B electronic market) to meet the needs of buyers and sellers (Ngai, 2003, cited in Chong, 2011). Gilmore et al. (2007) pointed out that e-marketing is a logical extension which can enable practices to create, disseminate and deliver customers value.

Specifically, e-commerce is usually divided into two key parts, namely, B2B and B2C. As an electronic platform, $\mathrm{B} 2 \mathrm{~B}$ e-commerce pays more attention to the products and services. Companies with small size usually rely on the electronics market, but companies with large size operate on platforms of their own, such as the company's website. Therefore, the electronic market is of great importance for different companies to conduct business through the Internet. Laudon and Laudon (2000) pointed out that the B2B electronic market has a close relationship with the payments via the Internet. Rohim, et al. (2004) defines the electronic market as an information system (IS) and people can implement transactions by working with the appropriate trading partners. According to Gulledge (2002), electronic markets, exchanges and centers are often considered to have different meanings. First, the electronic market is a virtual place for buyers and sellers to conduct business transactions. The exchange is a variety of services that are privately or publicly issued, such as spot purchases, auctions, catalog hosting, purchasing and non-purchasing activities. Finally, hub refers to the exchange of documents between organizations that support ecommerce transactions.

\section{E-Commerce in Developing Countries}

Developing countries are characterized as lack of large-sized firms and low level of investment in the infrastructure, as a result poor facilities in the information and communication. Since SMEs are in very large proportion among the businesses in developing countries, it is necessary to examine the possibility of application of e-business and e-commerce and to identify possible barriers and limitations.

First, SMEs can gain the advantage of reducing both the cost of information search and transaction by adopting e- 
commerce. The survey shows that some information is very important for SMEs. To be exact, the information can be achieved by using the Internet. Wikibooks (2012) claims that the Internet plays an important role in the process of realizing automatic packaging and distributing information.

Under this situation, five ways can be useful in understanding why Internet and e-commerce are useful for the entrepreneurs which are operated in the developing countries:

1) It helps SMEs to enter into the market all over the world.

2) Promote the tourism development in developing countries.

3) Promote the market of agriculture in the world market.

4) It gives access to B2B and B2G supply chains for companies in poorer countries.

5) It helps service providers in developing countries to operate efficiently and provide specific services all over the world.

While e-commerce is beneficial, SMEs will face some obstacles, as recently discovered in surveys conducted in some developing countries. Internal barriers are weak and internal communication infrastructure for SMEs lacks of ICT awareness and knowledge, inadequate ICT capabilities and cultural managers, and inadequate financial resources (Wikibooks, 2012).

In general, the main obstacles to increase the information technology and e-commerce usage are as follows (Wikibooks, 2012):

- People's understanding of the e-commerce is not that clear. A great number of SMEs in the world do not engage in e-commerce because they know the advantage of applying e-commerce in their business. From the traditional aspects, people believe that e-commerce can only be adopted by companies in large scale. Also they think the adoption of e-commerce will generate extra cost for their investment and it is not an easy thing to achieve return in a short time.

- The knowledge and skills of ICT is not enough. On the way of developing e-commerce, the role of people is very important. However, we have to admit that the technical literacy is limited in the developing countries all over the world. Under this situation, the number of the skilled workers in SMEs is not enough and this has become a key barrier in applying the information technology into the business. Generally speaking, SMEs have limited designing capabilities, so it is a difficult question about if SMEs can enter the global marketplace by making full use of the internet. While the Internet is useful for acquiring international design expertise, SMEs do not believe they can control their commodity prices unless they offer product innovation. However, they can take advantage of returns because they are low-cost suppliers.

In addition, in general, branded fashion companies have gained a premium in design. SMEs doubt whether the existence of the network will promote their brand recognition in the world.

- Financial expenses. For small businesses, the investment at the very beginning in adopting new technologies is large. On the way of attracting e-commerce, one of the key barriers is about high cost in the access of internet. With the emergence of the budget limitation, SMEs see the extra cost of ICT spending as a significant investment

A great number of SMEs find that the price of Internet marketing is very expensive. It is actually different between the fact of having website and having website with different traffics. The fist reason for saying this is that mass can be found by different users. The second reason for this is attributed to the SMEs' anonymity which is facing with different challenges. Because there are many companies on the Internet, brand recognition intends to be more critical on the way of becoming competitive. In addition, the user friendliness of the website is not enough and it is not updated in time. The search engine focuses on the query to the website and must widely disseminate website information. It is worth noting that more and more OECD countries prove that the e-marketing strategies are not a better alternative to traditional media formats. One effective might be to be responsible for establishing identification/branding through hyperlinks or updates.

- Infrastructure. In developing countries, their network infrastructures have their own characteristics. For example, low telecommunications density.

Safety. In the process of implementing e-commerce, the payment security and transaction privacy on the internet are of great importance. Despite the fact that some policies can be used to achieve the realization of the e-commerce, but there are still some obstacles on the way of applying the Internet to the online transactions. These obstacles are represented by the lack of trust. In addition, it is still not very popular for these people who are living in the 


\section{Challenges to be faced in the application of e-Commerce in Businesses}

Specifically, as to the development of current environment, it involves in the emergence of smart-phones and various kinds of social media. These have provided precious chances for companies to realize Internet marketing, such as marketing online. There are also many companies that offer goods and services such as retail online. Despite the quickly increase of business activities, there are still some limitations and challenges in Yemen's current situation. Basically, the challenge reflects the fact that countries are prepared to take e-commerce. There are many factors that can be used to view and assess countries' desire to adopt e-commerce. However, in fact, this can actually be influenced by different factors, such as the infrastructure of network and the Internet access cost. From the perspective of Goldstein and O'Connor (2000), e-commerce implementation should consider both the legal norms and technical standards. Here, it is a good time for people to find some key elements in adopting and implementing e-commerce in Yemen, the detailed information can be shown as follows.

First and foremost, Yemen has not developed well under the guidance of banking system, such as bank cash transfers and bank payments. For the e-commerce, it can't be separated with trustworthy banking system. In particular, although some payment options have been introduced and are available, payments on the Internet have not yet been determined. It is said that Yemenis are not familiar with the usage of credit and debit cards, online banking and payment through kiosks.

It is widely acknowledged that most businesses are not very large and they are owned by family, and it is difficult to make full use of new technology in their operation process. The one can be mentioned here is they need to pay attention to the emergence of the innovated business systems. For the younger generation who have good education and are very professional at using computer, they prefer to adopt marketing online. Under this situation, IT service companies are easy to be recognized in a short time and this is because those companies can build websites and the necessary e-commerce facilities.

In addition, poor Internet capacity and communication systems are considered to be the key factors which can limit the e-commerce implementation and marketing on the Internet. Although Yemen owns a telecommunications network system, this is really not enough to support the usage in the commercial aspects. The average data transfer speed is very low, and it requires installing transfer channels.

Finally, we need to look at the legal framework which is required to protect the information of organizations and individuals. Privacy and protection of information are essential in the successful implementation of e-Commerce. Yemen does not have adequate laws and regulations relating to the Internet and Internet-based businesses. Yemen lacks the system of proper identification of users in the Internet. For example, individuals are buying the SIM cards freely without registration.

\section{Opportunities of e-Commerce in Yemen}

To evaluate the opportunities of applications of e-Commerce in Yemen, we will borrow the framework of PEST and relevant business environment at micro-level. First of all, as 'political' environment, changes in the government's policies and regulations. An important and influential factor of the government policy is seen in terms of the active participation in the AEC (Asiean Economic Community). The community aims to develop the region as a global hub by integrating with the global economy. This move requires a strong cooperation among the countries in the region. This development is an opportunity for businesses as well as a threat to them. By upgrading self and linking with businesses in other countries, local firms can be able to move along with the trend. Otherwise, they will be left out in the changing environment. To upgrade firms with their connections and linkages to the other firms in the region and world, the adoption and implementation of new ICT is essential. The new business models and methods such as e-Business and e-Commerce are then possible to be implemented. Those businesses, especially SMES, which can adopt and apply the modern technologies and implement the new way of doing business, particularly e-Commerce, can gain substantial advantages. A part of the government's initiatives towards the development of private section and SMEs is also the encouragement of adoption of new technologies in businesses.

Yemen economy is still agri-based and most Yemen people are working in the primary sector. The income per capita is as low as below 350 USD (in 2011 the figure was 250.191). However, Yemen economy grew at a faster rate in the last couple of years after taking over the state power by the civilian government in 2010. The accelerating 
economic growth has increased also the demand for the goods and services by the consumers. The larger volume of demand for goods and services represent also the larger business transactions and the possibility of the use of Internet based business and commercial transactions. Moreover, an important aspect of the economy is increasing inflow of foreign direct investment (FDI) which amounted to 56.7 Yemeni Real billion as of June 2014. The rise in FDI will help local businesses to cooperate with multinationals whereby the modern practices of doing businesses are applied including e- Commerce activities.

It is said that the implementation of E-Commerce is influenced by the technological environment in a direct way. Yemen's technological development is still at the early stage, but the Internet and telecommunication system and infrastructure are advancing significantly. Internet connection was made first time in 2000 , but the access was very limited due to many factors including censorship (admin, 2015). The Internet however boomed in 2011 when the government changed the policy and opened the doors. The significant growth was made when Yemen Post and Telecommunication (YPT) discounted its SIM cards for GSM system at 2000 Yemeni Real which made affordable to all phone users. As a result, now, the rate of mobile penetration is over 50 percent, after 28.1 million SIMs being sold in the market, as reported by the Ministry of Telecommunication by 31st March 2015.

Based on the current challenges, the e-commerce readiness level is largely depended on the ICT dissemination and the institutionalization of an e-commerce environment (ITU, 2008). Infiltration and Internet access for PCs, laptops and tablets are growing over the past few decades in a stale speed. On the contrary, legal infrastructure is usually used to manage commercial transactions and the one can't be ignored here is that the consumers' rights can't be ignored. The barriers of Yemen's e-commerce have a close relationship with the old way of doing business and it is about the legal obstacles. From the perspective of the credit/debit card community, under the digital environment, some challenges have emerged and this can largely attributed to the fact that payments are finished online. In addition, due to limitation of the online banking regulations, the limited debit and credit community also restricts online users to build trust in the digital society. In addition, before the year 2008, credit bureau did not very well in managing risks in a strategic way. However, consumers did not have a credit history. Nowadays, things have changed greatly with the I-Score Bureau's establishment. In the first year, there were more than 4.3 million registered customers, and financial institutions began to use credit ratings, and more are approved by card applicants. It is found that approximately $40 \%$ of the population who are less than 18 years old cannot issue the credit/debit card, but this is really promising in the future and the digital payment transactions intend to become more and more popular. As to the legislation, Yemen's only law No. 15/2004 started to enact in the year 2004 and this law focuses on discussing the e-commerce. After having taken the law into consideration, it is no difficulty to find that it pays a lot of attention in analyzing the legal status under different electronic document. Moreover, it provides legal services for the Information Technology Industry Development Authority (ITIDA). It aims to approve the authority to verify the organization of the electronic document. In addition, in 2009, ITIDA launched the Yemeni Certification Authority (Root CA) and it focuses on talking about the effectiveness of different activities. Everything is done to enhance public trust in e-commerce and this is considered to be the key challenge. When it comes to the methods of payment, it can be greatly influenced by the customers' inner trust. Online transactions and payments Next, this is obviously magnified. According to statistics, in Yemen, the Internet use rate of the private sector is $60 \%$ compared with $15 \%$ of households. In fact, totally 5.4 million households can be found in Yemen and it is estimated that about twenty percent of them can't separate with the computer facilities. Since 2004, the government has been launching various e-government applications to encourage people to do online business. This contains the issuing of a driver's license, high school grades, etc. Table 2 shows the obstacles to the implementation measures of e-commerce in Yemen under the European Benchmark Test and E-Commerce Report (ECATT, 2000). It can be justified without any exaggeration that different influencing factors in the finance should be addressed by various stakeholders and this is an efficient way to summarize the different challenges faced by Yemen's e-commerce. Moreover, some social challenges can be found and it is represented by the lack of trust from the bottom of consumers' inner heart. Consciousness can be regarded as an indispensable factor in deciding the e-commerce interests achieved by customers and organizations. When comparing Yemen's mobile proliferation with Internet usage, it is easy to find that mobile users intend to spend same cost and the cost has a clear trend of increasing. This demonstrates that affordability is not the most important issues that should be considered. Internet access costs are reliable and it allows mobile commerce to penetrate. If the appropriate ecosystem is available, the training work is not enough and this has been considered as a key barrier in a network environment (Kamel and Fikry, 2007; Dutta and Mia 2009). When they are introduced into innovative technologies, this can be very confusing. For the electronic payment systems, one of its key challenges for new users is the lack of trust.

Resisting change is a more cultural factor, and it is not an easy thing to turn their habits. This is related to 
organizational factors, which are the younger generation of senior managers and middle managers. The gap between the ICT and the technical staff of ICT advocates. Finally, it is to understand the language barriers of online content. Most Yemenis can't understand the English language, but it is a pity that more than $82 \%$ of websites are made based on the English language. Due to the limitation of the Arabic words, online stores are not very popular among these people who have great interests in developing online communities. After the year 2011, Yemen has experienced a sharp growth in the social media. This not only has aroused a certain impact on the e-commerce community's development but also has different impacts towards the economy development.

Table 2: Barriers to eCommerce in Yemen

\begin{tabular}{|c|c|}
\hline Barriers & Remarks \\
\hline Lack of awareness of added value & $\begin{array}{l}\text { Under the influence of proper distributed access and/or security issues, } \\
\text { companies and users lack interest in online shopping, and thus have considerable } \\
\text { suspicions about the added value of e-commerce. }\end{array}$ \\
\hline $\begin{array}{l}\text { Suitability of products for } \\
\text { Distribution }\end{array}$ & $\begin{array}{l}\text { Yemen's statistics show that } 48 \% \text { of online shoppers' online shopping is mainly } \\
\text { due to lack of product supply in the local market, convenience of online } \\
\text { comparison of products }(32 \%) \text {, comparison of prices }(24 \%) \text { And easy to pay } \\
(21 \%) \text {. }\end{array}$ \\
\hline Costs and performance & $\begin{array}{l}\text { The limitations of narrowband access have hampered the development of e- } \\
\text { commerce; online shopping is considered by many to be expensive rather than } \\
\text { an effective alternative to traditional shopping. }\end{array}$ \\
\hline Data security & $\begin{array}{l}\text { Compared with private value-added networks, the Internet poses considerable } \\
\text { security problems due to its open architecture, and specific technical measures } \\
\text { are needed to ensure the security and reliability of data exchange, which is } \\
\text { expensive. There is a need to improve security and allow other payment methods } \\
\text { to supplement the use of credit cards, such as cash on delivery, for local } \\
\text { consumers, and to allow for trust and reduce consumer concerns about the details } \\
\text { of payment over the Internet. }\end{array}$ \\
\hline Consumer protection & $\begin{array}{l}\text { In } \mathrm{B} 2 \mathrm{C} \text {, building trust requires taking steps to protect consumers from fraud and } \\
\text { to give them consumer protection when shopping online. There is a need to raise } \\
\text { buyer awareness and participate in online shopping to meet their concerns about } \\
\text { personalized data collection that may be used for other purposes, which can be } \\
\text { handled through copyright notices or new intellectual property laws. }\end{array}$ \\
\hline Lack of critical mass & $\begin{array}{l}\text { The online market works well under the co-work of different consumers and } \\
\text { suppliers. Yemen has a small market, and this problem can be alleviated by } \\
\text { market segments diversification. }\end{array}$ \\
\hline
\end{tabular}

With regard to technical challenges, some problems have emerged due to the weak telecommunications infrastructure. It involves the bandwidth costs which can result in long periods of access and download. As to the challenges in the perspective of finance, one of the most representative one is about the lack of effective and secure electronic payment system. For credit or debit cards, one of the key challenges can be attributed to the lack of awareness in using these cards. On the Internet, it is very common for consumers to finish the transactions by using various kinds of bank cards. There are also tax issues and obstacles in the process of spreading e-commerce. Moreover, the positions of the governments can actually reflect the requirements of using information networks. This lays a solid foundation for the chosen of the transactions treatment and traditional methods. For example, taxing products can be purchased on the Internet. In Yemen, economy can't be separated from taxes and tariffs and this is because they have long been considered as reliable income source. These challenges ought to be strategically addressed based on appropriate allocation of mechanisms and resources. Different opportunities can be found to develop a solid e-commerce infrastructure in Yemen.

As for the opportunity, the government initiated a comprehensive method to work with the National Postal Service (NPA). This method is regarded as the key government initiative in the process of promoting the development of the e-commerce and it is a good way to realize the primary distribution. From the perspective of NPA, it plans to create a network which can better connect 3,000 branches across 22 provinces in Yemen. As the country's only organization, it not only appears at the village level but also exceeds what the banking industry can achieve. It can be justified without any exaggeration that its branches are located in different areas which spread in approximately four thousands villages and rural areas. It is said that it can be helpful in transforming among different classical developing countries - such as the current digital divide, to bring their communities into the community (Kamel, 2009a). In the world, postal services are considered to be the most respected brands. This is very obvious in Yemen because it can provide physical transport networks. Through e-commerce, these services can be optimized for 
global exposure, and it provides latest information to their customers (ITU, 2008).

In Yemen, its digital economy still stays in its construction stage. Despite the fact the scale of this country is small, but it actually has a dynamic e-commerce platform. Specifically, the Internet creates approximately $\$ 200$ million to the economy in 2011, and it is almost equivalent to about $1.2 \%$ of the country's gross domestic product (BCG, 2012). As to the positive influence of the internet, one of the most obvious one is that it can drive the development of the digital economy. Meanwhile, tremendous potential can be found in the investment process. In the 2011-11 fiscal year, the Yemen ICT industry generated revenue of approximately $\$ 1.3$ billion, compared to $\$ 2.7$ billion in the 2009-2010 fiscal years; during this stage, ICT revenue growth rate has reached $6.5 \%$. ICT sector contributed $4.2 \%$ and $4.6 \%$ to Yemen's gross domestic product (GDP) in fiscal year 2009-2010 and fiscal year 2011-2012 respectively. In 2010-2011, the growth rate of ICT sector in Yemen can reach 7\% and this rate has reached 13\% in 2009-2010.

Although the digital purchase amount of consumers in the modern life plays an important role in measuring the influence of the Internet on Yemen's economy. The forecast shows that total contribution will triple by 2017, and it will reach $1.6 \%$ of total GDP (BCG, 2012). But it is worth nothing that Yemen's businesses have yet grasped the important business potential and capabilities of the Internet. Some industries can benefit from the digital economy, such as tourism, where the online market for tourism and travel services is $\$ 1.8$ billion, with Yemen's travel company using 5\% (BCG, 2012). It is estimated that e-commerce contributes \$229 million which accounts for only $0.1 \%$ of Yemen's GDP (BCG, 2012). This data has created key differences when comparing with other countries which have gradually realized the importance of developing the Internet economy. In the year 2011, online advertising accounted for 4\% of Yemen's advertising consumption (BCG, 2012). This means that the B2B economic activity model which is generated by the Internet has posed a great challenge towards the advertising space. It represents the most popular platform in the country and it attracts more than 15 million people in Yemen and attracting in the Middle East. More than 400 million people (Ahmed, 2007b). Under this situation, the digital economy can largely be influenced by both the social services and inclusion. In order to control the purchase and guarantee the food distribution fairness, the Yemeni government pays a lot of attention to increase the food subsidies efficiency (BCG, 2012).

Information and communication technologies can help alleviate poverty, improve the problems emerged in the health care department, equitably allocate resources and stimulate people to take part in the decision-making processes. So, as an ICT tool, the influence of the Internet should not be checked solely on the basis of the absolute number of individuals involved, but should be measured more based on its contributions to the progress of the social economy. Under this situation, it is of great importance to pay attention to the Internet and its impacts on Yemen. Internet has long been considered as a business platform to accelerate the trading amount, increase investment, and promote the transactions of businesses. Moreover, as a marketing tool, it has generated an unprecedented opportunity (EIU, 2001). With the expansion of young Yemen, many people choose to start their own businesses, mainly to provide different products and services that the community urgently needs. This trend is considered to have different effects which are positive. For example, it meets different needs, creates job chances, reduces youth unemployment, and improves the economic conditions of many people. In addition, Bell, (1998) points out that Yemen will become efficient and profitable by getting a good knowledge of the current e-commerce ecosystem. It is estimated that there are more than 8,000 websites in Yemen. The one can be mentioned here is that no more than $10 \%$ of them are dedicated to e-commerce. Also only a few e-commerce and e-commerce sites and the portal uses online payment methods, most of which still rely on COD. Meanwhile, Kamel and Abdel Ghaffar (2004) claim the importance of some other payment methods. Specifically, they are debit cards and mobile payments.

\section{Conclusion}

In conclusion, based on the above mentioned contents, it is no difficult to find that employment of consumers can get more chances from the existence of e-commerce. Based on the above mentioned contents, e-commerce infrastructure needs to be reliable. Specifically, it contains the speed of Internet, the methods of payment, and the protection of payment. It is really necessary and imperative to raise awareness programs to alleviate and even solve the e-commerce issues. Just as what has been mentioned above, e-commerce business accounts for about $5 \%$ of the total purchase amount and this has actually provide a good chance for companies.

Besides, the article provides an overview of Yemen's e-commerce ecosystem and the challenges it is facing. The number of people shopping online has increased relatively. More and more individuals still take responsibility for purchasing and paying from the Internet by making full use of their friends and third-party enterprises. The reason 
on why people can actually learn a lot from the internet can largely be attributed to the fact that Internet provides technology access, authenticity of products, communications, and even entertainment project. Yemenis do very well in online shopping and they can complete the regulated work as soon as possible.

In addition, despite the fact that some people do not buy online, but they still face some infrastructure challenges. And one of the most obvious one is about the reliable payment system. For these global payment system providers, they not only offer payment services which are very convenient, but also focus on preventing fraud and making buyers understand Internet-related risks in a better way. Moreover, it is no difficulty to find that the service of Yemen's transportation and logistics do not completely combine the emergence of Internet. Transportation costs seem to become a key challenge for these people who are willing to shop online. Some people still choose to deliver their service by using the third-party entities. International airlines seem to have received delivery from the Yemen market. The postal service in Yemen seems to be losing market opportunities.

Last but not least, the legal framework of Yemeni is required to give specifications to business transactions. In addition, it should provide protection against cyber-crime. The Yemeni governors must be able to develop the infrastructures which are represented by electricity and transportation. Most importantly, only in this way can they better serve for e-commerce.

\section{References}

1. Al Rawabdeh, W., Zeglat, D., \& Alzawahreh, A. (2012). The importance of trust and security issues in ecommerce adoption in the Arab World. European Journal of Economics, Finance and Administrative Sciences, (52), 172-178. Retrieved from http://www.scopus.com/inward/record.url?eid=2-s2.084873515910\&partnerID=tZOtx3y1

2. Al-Aghbari, A., Abu-Ulbeh, W., Ibrahim, O., \& Saeed, F. (2015). The readiness and limitations of egovernment in yemen. Jurnal Teknologi, 73(2), 107-115. Retrieved from http://www.scopus.com/inward/record.url?eid=2-s2.0-84925361789\&partnerID=tZOtx3y1

3. Al-mamary, Y. H., Shamsuddin, A., \& Aziati, N. (2015). Investigating the Key Factors Influencing on Management Information Systems Adoption among Telecommunication Companies in Yemen : The Conceptual Framework Development, 6(1), 59-68.

4. Al-wazir, A., \& Zheng, Z. (2014). Factors Influencing E-government Implementation in Least Developed Countries: A Case Study of Yemen. Developing Country Studies, 4(7), 20-30. Retrieved from http://www.iiste.org/Journals/index.php/DCS/article/view/12184

5. Ali, S., \& Al-Jabri, A. (2011). Oman's National Payment Systems and their Compliance with International Standards and Practices. Journal of Internet Banking and Commerce, 16(3), 1-25. Retrieved from http://search.proquest.com/docview/1010389426? accountid=35812

6. Alkibsi, S. M., \& Lind, M. (2011). Customer perceptions of technology-based banking service quality provided by banks operating in Yemen. International Journal of Strategic Information Technology and Applications, 2(3), 35-82. http://doi.org/10.4018/jsita.2011070104

7. Anonymous (2015a). Mobile Mania: One of the last great "unphoned" temtories opens up. Bago and Yagon, 24th January, 2015. Retrieved from http://www.economist.com/news/business/21640355-one- last-greatunphoned-territories-opens-up-mobile-mania.

8. Ash, C. (2005). Managing eBusiness Change Within a Global eMarketplace: A Buyer's Perspective. ECIS 2005 Proceedings, Paper $78 . \quad$ Retrieved from http://aisel.aisnet.org/cgi/viewcontent.cgi?article=1099\&context=ecis2005.

9. Bakos, Y. (1998). Emerging Role of Electronic Marketplaces in Internet. Communication of the ACM, 41(8), 35-42. Retrieved from http://citeseerx.ist.psu.edu/viewdoc/download?doi=10.1.1.83.180\&rep=rep1 \&type=pdf.

10. Berry, L. (1995). Relationship Marketing of Services- growing interest, emerging perspectives. Journal of the Academy of Marketing Science, 23 (4), 236-45.

11. Bhat, K. A. (2014). A sian R esearch C onsortium Impact of Information Communication Technology ( ICT ) on Public Administration. Asian Journal of Research in Social Sciences and Humanities, 4(4), 273-286.

12. Chong, W. K. (2011). The Design and Development of an E-Marketing Framework for Asian B2B Marketplace. Thesis, University of Bolton. 
13. Chong, W. K., Shafaghi, M. \& Tan, B. L. (2011). Development of a business-to-business critical success factors (B2B CSFs) framework for Chinese SMEs. Marketing Intelligence \& Planning, 29 (5), 517 - 533. Retrieved from http://dx.doi.org/10.1108/02634501111153700.

14. Chopra, S., Dougan, D. \& Taylor, G. (2001). e-Commerce Opportunities. Supply Chain Management Review, May/June 2001, 50-58.

15. Gawady, Z. M. El. (2005). The Impact of E-commerce on Developed and Developing Countries Case Study : Egypt and United States, (November), 1-28.

16. Goldstein, A. \& O’Connor, D.E. (2000). E-commerce for development: prospects and policy issues. Technical Papers No. 164, OECD Development Centre, Paris.

17. Gulledge, T. (2002). B2B eMarketplaces and small- and medium-sized enterprises. Computers in Industry, 49, 47-58.

18. Gunasekaran, A., Marri, H. B., McGaughey, R. E., \& Nebhwani, M. D. (2002). E-commerce and its impact on operations management. International Journal of Production Economics, 75(1), 185- 197.

19. Keikhayfarzaneh, M. M., Keikhayfarzaneh, A. R., Khalatbar. J \& Sourizaei, M. (2011). The Role of ECommerce in Electronic Customer Relationship Management (ECRM) and the Factors Affecting It. International Journal of Scientific \& Engineering Research, 2(8), 1-3. Retrieved from http://www.ijser.org/researchpaper\%5CThe_Role_of_E_Commerce_in_Electronic_Customer_R elationship_Management_(ECRM)_and_the_Factors_Affecting_It.pdf.

20. Laudon, K. C. and Laudon, J. P. (2000). Management Information System: Organization and Technology in the Networked Enterprise, Prentice Hall.

21. Lin, C., Huang, Y-A., Jalleh, G., Liu, Y-C. and Tung M-L (2010). An Exploratory Study of Factors affecting Adoption and Implementation of B2B e-Commerce in Australian Health Care Organisations, International Journal of Electronic Commerce Studies, 1(2), 77-96.

22. Lo, B. W. N. \& Gong, P. (2005). Cultural Impact on the Design of E-Commerce Websites: Part I: Site Format and Layout. Issues on Information Systems, 6 (2), 182-188. Retrieved from http://iacis.org/iis/2005/Lo_Gong.pdf.

23. Mamaghani, F. (2010). The Social and Economic Impact of Information and Communication Technology on Developing Countries : An Analysis. International Journal of Management, 27(3), 607-616.

24. Papadopoulon, P., Kanellis, P. \& Martakos, D. (2002). Trust Formation and Relationship Building in Electronic Servicescapes. ECIS 2002, June 6-8, Gdansk, Poland. Retrieved from http://onemvweb.com/sources/sources/relationship_quality.pdf.

25. Rainer and Cegilski (2011). Introduction to Information Systems: Supporting and Transforming Business. (3rd ed.). Hoboken, NJ: John Wiley \& Sons.

26. Rauyruen, P., Miller, K. E. \& Barrett, N. J. (2007). Relationship Quality as a Predictor of B2B Customer loyalty. Journal of Business Research, 60(1), 21-31. Retrieved from http://onemvweb.com/sources/sources/relationship_quality.pdf.

27. Samanta, I. \& Kyrozopoulos, P. (2008). Managers' Perceptions of Using of e-Marketing in B2B Relationships. SPOUDAI, 58 (3-4), University of Piraeus, 126-147.

28. Terzi, N. (2011). The impact of e-commerce on international trade and employment. Procedia - Social and Behavioral Sciences, 24, 745-753. http://doi.org/10.1016/j.sbspro.2011.09.010

29. Zolait, A. H. S., Ibrahim, A. R., \& Farooq, A. (2010). A Study on the Internet Security and its Implication for E-Commerce in Yemen. International Journal of Technology Diffusion (IJTD), 1(3), 34-47. 